\title{
Participação e cultura política no Orçamento Participativo
}

\author{
Euzineia Carlos*
}

\section{Considerações iniciais}

Os espaços públicos participativos da Nova República emergem em suas possibilidades de reelaboração dos ideais democráticos de soberania popular, de organização autônoma da sociedade e de reinvenção de suas relações com o estado, requerendo a necessária reversão do pretérito padrão de interações marcadamente de tutela, subordinação e dependência.

A crescente difusão de experiências de participação popular na esfera pública municipal, no Brasil, tem demonstrado o quanto a realização do potencial de democratização destas experimentações - educação políticopedagógico, redistribuição de recursos e justiça social, pluralidade de atores, construção de espaços públicos - guardam relação direta com a especificidade sociológica e histórica em que se inserem, uma vez que envolvem e requerem a construção de práticas e interações sociais, pelos atores que estão na arena discursiva, que favoreçam o processo democrático. Nesta

* Mestre em Planejamento Urbano e Regional pelo Ippur/Ufrj, leciona na Ufes; pesquisa em andamento: "Dimensões da Democracia Participativa no Projeto Terra" (apoio: Facitec).

Texto baseado em dissertação de mestrado intitulada Controle social e política redistributiva: as experiências de orçamento participativo de Vitória e Serra, apresentado no XXV Congresso da ALAS (22-26 ago. 2005, Porto Alegre). Mail: euzineia@hotmail.com.

\begin{tabular}{|l|l|l|l|l|l|}
\hline Civitas & Porto Alegre & v. 6 & n. 1 & jan.-jun. 2006 & p. 131-154 \\
\hline
\end{tabular}


perspectiva, longe de serem processos tecnificáveis e pasteurizáveis, os espaços públicos de participação correspondem a processos essencialmente políticos que envolvem e implicam um conjunto de significações culturais e gramaticais que são próprios a cada tempo e a cada espaço.

Nesta perspectiva, ao processo de construção da democracia reúne-se, ao lado da construção de instituições democráticas, a ênfase nas subjetividades, representações e valores como seus elementos, concomitantemente, constitutivos e constituídos. Uma nova abordagem da democratização que busca mostrar que a vigência da democracia implica também a incorporação dos valores democráticos "às práticas cotidianas" (Avritzer, 1996, p. 143). Uma concepção de democracia que valoriza na construção da forma democrática a construção de uma gramática social e cultural de modo articulado a inovação institucional (Santos e Avritzer, 2002).

A releitura e aproximação das concepções de cultura e política que esta noção de democracia remete, provocadas, por um lado, pela inflexão no campo da teoria democrática e, por outro, pela trajetória dos movimentos sociais (Dagnino, 2000), finca bases em uma

cultura entendida como concepção de mundo, como conjunto de significados que integram práticas sociais, [que] não pode ser entendida adequadamente sem a consideração das relações de poder embutidas nessas práticas. A compreensão da configuração dessas relações de poder não é possível sem o reconhecimento de seu caráter "cultural" ativo na medida em que expressam, produzem e comunicam significados (Alvarez, Dagnino e Escobar, 2000, p. 17).

A valorização e ênfase na democracia enquanto forma gramatical socioistórica tem orientado análises que buscam penetrar o tecido das relações sociais e da cultura política gestadas no nível dos processos de transformação da institucionalidade democrática, revelando as modificações e permanências aí observadas, através de uma reconstrução do padrão concreto de relacionamento entre o estado, as instituições políticas e a sociedade, mostrando que nessas interfaces habita o movimento de consolidação da democracia.

Este artigo valoriza a análise da relação entre espaços públicos de participação e a cultura política dos atores locais, enquanto uma das variáveis dos resultados alcançados pelos processos inscritos às novas institucionali- 
dades democráticas, tendo como referente empírico as experiências de Orçamento Participativo (OP) de Vitória e Serra, ES, no período de 1989 a 2003. ${ }^{1}$

A escolha da cultura política como variável explicativa dos resultados alcançados pelos processos participativos e para efetivação de seus potenciais impactos para a democratização, fez-se considerando duas ressalvas principais: 1) que a complexidade intrínseca dos processos de participação torna qualquer tentativa de delimitação de um número restrito de variáveis um sentido simplificador dos processos sociais e, por outro lado, que estas não podem ser tomadas em absoluto, como determinantes, e sua eventual ausência vista como impedimento, mas, no máximo, como obstáculo à realização do potencial de democratização do processo decisório; 2) as diferenças observadas nos formatos de participação e na dinâmica das interações discursivas em Vitória e Serra podem ter importante relação com suas diferenças substantivas no nível de organização da sociedade civil e na cultura política local.

A literatura tem apontado que a consistência da cultura participativa existente na sociedade civil tem um papel fundamental no grau de profundidade que podem alcançar os processos participativos: a organização da sociedade, a existência de entidades representativas sólidas, o conhecimento destas entidades na defesa dos cidadãos e na relação com outros atores, determinam seu grau de capacidade em participar com autonomia e de ocupar qualitativamente a complexidade dos espaços participativos. Nestes termos, as práticas e representações sociais presentes em cada experiência, na arena de confronto com os projetos políticos das forças dirigentes locais, podem se manifestar como avanços ou recuos para a construção democrática.

Variados estudos têm sugerido (Avritzer, 2002; Wampler, 2003; Silva, 2003; Lüchmann, 2002; Teixeira, 2002), que na análise da renovação ou da persistência dos resultados alcançados pelos processos participativos no sentido da efetivação de seus potenciais impactos para a democracia na gestão municipal, comparecem uma infinidade de variáveis que condicionam sua implantação e desenvolvimento. Dentre estes elementos condicionantes, vem sendo recorrentemente enfatizados, além da cultura política, o projeto político e o compromisso governamental e o desenho institucional do arranjo participativo. 
Nesta análise, em que pesa as características da cultura política dos atores presentes na arena decisória e as suas relações com a estrutura participativa, é fundamental a compreensão acerca dos vínculos associativos, da trajetória associativa, da tradição de lutas e da densidade movimentalista da sociedade civil. Conforme nos diz Avritzer (2003, p. 46), a composição da sociedade por uma cultura política em que esteja presente uma tradição associativa é fundamental para as experiências participativas, tanto na estruturação da prática, como na geração de maior participação e, com isso, no aprofundamento da tradição política associativa. Diz ele, o associativismo comunitário é importante pela sua "capacidade de forjar o sucesso inicial da proposta de participação e na capacidade de democratizar a relação entre estado e sociedade civil, através de um crescimento constante da participação". Nesta perspectiva, a prática participacionista nos espaços públicos, quando podem contar com uma estrutura associativa preexistente aos novos arranjos participativos, pode incidir positivamente sobre a cultura política local, fortalecendo as características da cultura associativa e gerando novos elementos democratizantes.

\section{Cultura política e participação}

O desenvolvimento das experiências de OP em Vitória e em Serra resultaram em marcantes diferenças nos modelos de participação adotado que, por sua vez, guardam relação com os contextos políticos diferenciados em que estão inscritos, de desigual composição dos projetos políticos ${ }^{2}$ e de comprometimento governamental, e, de culturas políticas e quadro associativo igualmente diferenciadas. Embora seja difícil e, ao mesmo tempo, frágil o exercício de comparação entre experiências peculiares, a análise aqui empreendida permite algumas considerações de plano geral, sobre o modo como a cultura política se relaciona com os arranjos participativos, interferindo em seu potencial resultado democratizante. Preocupa-se, então, em investigar se os processos de participação desenvolvidos em realidades político-culturais frágeis e inconsistentes podem interpelar os governos com a mesma força que os contextos mais coesos e democráticos.

2 A noção de projeto político diz respeito ao conjunto de crenças, interesses, concepções de mundo e representações que orientam a ação política dos diferentes sujeitos (Dagnino, 2002). 
Para efeitos da avaliação dos resultados democratizantes do orçamento participativo e de sua relação com a cultura política local, a sociedade civil e os atores sociais das experiências analisadas são aqui considerados a partir dos traços comuns à sua prática associativa. Obviamente, a sociedade civil não é composta de forma unitária, mas sim é caracterizada por uma forma multifacetada, diversa e difusa, inserida em um mosaico de cultura política ambivalente e híbrida. Deste modo, para a análise aqui delineada, considerase a sociedade civil local a partir de suas práticas e relações confluentes, de modo a observar suas inter-relações com os arranjos participativos.

\section{Fragilidade da sociedade civil versus participação autônoma}

A análise da participação da sociedade civil no orçamento municipal em Vitória e Serra, se constrói inicialmente a partir da avaliação do quadro característico da cultura política local, tendo como base o resgate da história de seus movimentos populares e de sua trajetória associativa e de lutas no período precedente a implementação do OP. Entre os dois municípios, verifica-se uma expressiva diferença quanto ao padrão político-cultural, tanto pelo perfil dos atores sociais, como pela forma de atuação e de relação da sociedade com o estado. Aspectos estes que serão aqui destacados.

O quadro associativo da sociedade em Vitória passa a ganhar contornos expressivos apenas a partir do início da década de 80 , período em que são criadas grande parte das associações de moradores e entidades civis existentes $(62,8 \%$ destas foram criadas de 1981-85). Este avanço na organização popular na Capital foi marcada pela criação, em 1984, do Conselho Popular de Vitória (CPV) que buscava unificar o movimento popular de caráter reivindicativo e fortalecer os mecanismos de luta populares. É nesta década que Vitória vive o auge do associativismo comunitário, cujo ciclo de mobilização havia dado à sociedade civil sua máxima densidade. As reivindicações por melhoria nas condições de vida urbana estavam, pouco a pouco, se articulando ao ideal de se constituir junto à administração municipal novos espaços de interlocução que permitissem a democratização dos negócios públicos.

No entanto, a moldura associativa e movimentalista montada não foi capaz de articular-se frente a um estado de antigas formas de representação política integradoras, assistencialistas e clientelistas, que, ao perceber as 
conquistas do movimento popular, mobilizou-se e interferiu no processo de cunho popular no sentido de sua desestabilização, desarticulação e alijamento de lideranças e entidades opositoras: "a Prefeitura de Vitória estabeleceu uma postura política visando à desmobilização das organizações comunitárias; institucionalizando o 'paralelismo', criando associações fantasmas, cooptando lideranças (...)” (PMV, 1990).

Em resposta ao movimento popular reivindicatório, o executivo local incentivava e privilegiava a participação de cunho instrumentalista, reforçando o padrão de relação clientelístico. Na participação instrumental a ênfase dos trabalhos das associações de moradores era voltada à distribuição de tíquetes de leite, à realização de palestras, seminários e cursos de formação e profissionalizantes, indicando a transformação dos movimentos de bairro em extensão da máquina pública, executando a custo zero tarefas que caberiam ao estado, em que o trabalho comunitário é tomado apenas e restritamente como uma forma de reduzir o custo da ação governamental.

O reflexo da política clientelista adotada pelo executivo local é possível de ser observado, em certa medida, no formato organizacional e de funcionamento do movimento popular, assim como na sua forma de atuação e de relação com o poder público: pouco envolvimento das bases e de parte da diretoria na tomada de decisões, expressado pelo pequeno número de pessoas nas reuniões das associações de moradores; a grande maioria das associações não reúnem-se com regularidade; as assembléias de bairros que reúnem um número expressivo de moradores se limitam àquelas que se destinam a distribuição de tíquetes de leite do Programa Nacional de Leite para Crianças Carentes (PNLCC); o número de pessoas envolvidas no trabalho cotidiano das associações variam de um a dez; o processo decisório é concentrado nas mãos do presidente da associação ou da diretoria; a principal atividade desenvolvida pelas associações nos dois últimos anos da década de 80 foi a reunião com dirigentes de outras organizações e grupos, seguida por encontros para distribuição de tíquetes de leite; os meios para encaminhar suas reivindicações envolvem o contato direto com autoridades (ofícios, audiências, presença de políticos nas reuniões) (PMV, 1990).

Pode-se dizer que, ao final da década de 80, as entidades de bairro de Vitória, em sua maioria, apresentavam um quadro caracterizado por um movimento popular desarticulado, desmobilizado, dependente em grande medida 
do apoio e de ações do poder público e das lideranças comunitárias, apesar do ciclo de mobilização vivido em meados dessa mesma década e, sobretudo, da existência de algumas lideranças e entidades com propósitos e atitudes mais democráticas. De acordo com Herkenhoff (1995),

a trajetória dos movimentos populares de Vitória gerou tanto lideranças mais conservadoras, com atitudes antidemocráticas e com um perfil de subordinação às práticas clientelistas, quanto lideranças com propósitos e atitudes mais democráticos, que buscaram um rompimento com as formas de organização mais tradicionais, pautadas pelo clientelismo. [...] No entanto, é a minoria que possui uma mentalidade democrática e participativa (p. 156).

Ainda como traço da cultura política híbrida, é possível destacar no movimento popular de Vitória da década de 80, algumas iniciativas que expressavam tentativas de inovação no interior do movimento, quanto ao fomento de um novo conteúdo orientado pela proposição de políticas, ao revés de seu pretérito caráter reivindicativo e imediatista. ${ }^{3}$ No entanto, as práticas associativas que emprestaram um novo caráter político à participação, novos valores, novas formas de organização (presentes entre algumas lideranças e entidades de base), não foram capazes de gerar rupturas e transformações no movimento popular como um todo. Em seu conjunto se destacava a existência de uma "cultura da dependência" (Herkenhoff, 1995), constituída na arena das práticas políticas locais de assistencialismo e cooptação que retrata uma ausência de autonomia das entidades populares, dependentes do protagonismo do estado e da ação do líder comunitário, que personifica as conquistas comunitárias.

Por outro lado, tem-se no município de Serra um movimento social caracterizado pela formação de uma sociedade civil mais coesa e consistente, que se fortaleceu na tradição de atuação junto aos movimentos populares da

3 A exemplo da elaboração de anteprojeto de lei enviado a Câmara pelo CPV em conjunto com algumas entidades de bairro (1987), que propunha a elaboração do orçamento municipal com participação popular. Assim falou um representante do CPV ao se referir à proposta de participação popular na elaboração do orçamento municipal enviada à Câmara: "Pro Hermes, participação popular significa cooptação [...], pro Conselho Popular o discurso de participação não estava muito claro [...]. A gente só sabia uma coisa: aquele tipo de participação popular não encaixava no que a gente pensava. A gente achava que os bairros tinham que ser respeitados na sua autonomia e na sua organização. E não ter o Estado, no caso a Prefeitura, influindo diretamente nas decisões" (Entrevista apud Machado, 1992, p. 21). 
década de 80 e no confronto com os poderes constituídos, conquistando mudanças nas relações estabelecidas com o estado, ao revés das formas de controle pretérito de tutela e subordinação e, atuando como ator na construção de um novo cenário político no município.

Com origem no movimento popular de caráter reivindicatório, assentado na atuação das associações de bairro e das Comunidades Eclesiais de Base (CEBs), a sociedade civil em Serra inaugurou uma nova fase em sua esfera organizativa através da criação da Federação das Associações de Moradores de Serra (Fams), em 1984, por meio da qual pode experimentar novas práticas e representações que superasse a atitude meramente reivindicativa típica dos movimentos da época e se inscrevesse em um papel mais propositivo.

A Fams, entidade que ao longo de sua existência colocou o município de Serra como uma referência de organização popular, consolidou internamente em seu primeiro congresso, em 1986, a proposta de implantação do orçamento participativo, embebida no discurso de participação popular, descentralização e transparência na gestão pública. O movimento popular, fortalecido pela sua Federação, não recuou frente às forças políticas adversas à democratização e à reversão do padrão de relações pretéritas, presentes na administração local. Ao contrário, organizou-se, articulou as entidades, elaborou propostas para o executivo em forma de projeto de lei e avançou sobre a câmara municipal no sentido de garantir institucionalmente suas demandas pela democratização da gestão local. Após muitas negociações, apenas em 1994 foi aprovado projeto de lei que criou a Assembléia Municipal do Orçamento (AMO), que viria a protagonizar todo o processo de feitura do orçamento participativo, juntamente com a Fams.

Para o movimento popular de Serra, apesar das hostilidades do executivo local em estabelecer novas relações com a sociedade orientadas pelos ideais democráticos, cada conquista se expressava como um novo vigor aos atores sociais com o fim de implementação do orçamento participativo. Nas palavras de um ativista dos movimentos populares de Serra: "A cada congresso da FAMS era reafirmada a necessidade de implementar o orçamento participativo no sentido de acabar com as desigualdades sociais, com a concentração de recursos em bairros privilegiados e a concentração do dinheiro nas mãos do prefeito e vereadores" (Entrevista, 2002 apud Carlos, 2003). 
O protagonismo do movimento popular se mostrou tão presente que, já no ano seguinte à criação da AMO, a FAMS organizou a elaboração do orçamento participativo com a adesão de alguns poucos técnicos da prefeitura, a despeito do executivo. Foram realizadas assembléias nos bairros, nas regionais e assembléias gerais, desenvolvidos grupos de trabalho e comissões setoriais para elaboração da proposta orçamentária para o ano de 1997. Como era de se esperar, desconsiderando a densidade da organização e deliberação popular, o executivo municipal não executou sequer uma única obra prevista no orçamento participativo. Assim, descreve-se aquele momento:

Naquela época possuíamos todos os requisitos para o êxito do Projeto em Serra. Possuíamos uma Lei Municipal que assegurava a discussão, possuíamos uma forte organização do movimento popular, entretanto, faltava um requisito essencial para a concretização do Projeto, a saber: a vontade política (Teixeira, 1995).

Uma história de lutas e conquistas do movimento popular em Serra que, ao mesmo tempo que demonstra as possibilidades de protagonismo societal, evidencia a necessidade de simbiose entre os projetos políticos do governo e os da sociedade civil, tendo em vista a concretização da forma democrática.

Como se vê, o desenvolvimento das experiências de participação em análise se dá em um cenário político-cultural diferenciado que, se em Serra conta com atores sociais mobilizados, organizados e articulados para o embate político necessário à democratização da gestão pública, em Vitória, convive com um movimento popular marcado por uma trajetória de dirigismo e manipulação, fruto da política clientelística e paternalista do governo local e, por outro, da parca contextura da sociedade civil. Em Vitória, as relações assimétricas de poder teceram um painel de desarticulação, desmobilização, dependência e fragilidade da sociedade frente ao poder público, muito embora coexistisse com um incipiente e pouco expressivo quadro de consciência dos direitos sociais e da importância da participação na gestão da cidade.

\section{Construindo a democracia nos espaços públicos de participação}

$\mathrm{Na}$ consolidação da democracia, a existência de regras e procedimentos claros, públicos e conhecidos são garantia de universalidade e confiabilidade de um determinado processo que finca bases em confrontos e negociações entre os atores. Ao contrário dos que consideram a valorização de regras como formalismo ou apego à burocracia, entende-se que a existência de "regras do jogo" é 
imprescindível à construção democrática, uma vez que pode proporcionar maior confiança à população quanto ao lugar que pode ocupar numa real partilha do poder, ao revés da tradição de livre-arbítrio quase total do executivo na condução do processo decisório. A elaboração de regras que orientem procedimentos flexíveis capazes de reger as ações de forma autônoma, não de caráter irrevogável, mas modificáveis se novo consenso assim determinar, num processo permanente e inovador são elementos imprescindíveis à moldura de novas institucionalidades. Como nos diz Lüchmann (2002, p. 143), "enquanto resultante das articulações estado e sociedade, o desenho institucional configura-se como o conjunto de regras, critérios, espaços, normas, leis, que visam fazer valer e promover a realização prática dos princípios democráticoparticipativos".

Sob este prisma, percebe-se no processo de OP de Serra - realizado com adesão do governo local apenas a partir de 1997, com Sérgio Vidigal (PDT) um desenho institucional bem definido, com regras claras, construídas socialmente, conhecidas, estáveis, que garantem uma participação ampla e uma boa confiabilidade ao processo de eleição de demandas e de representantes populares. As mudanças observadas ao longo dos anos de experimentação do processo foram fundamentadas no diálogo constante entre atores sociais e estatais. O funcionamento da instância de maior abrangência e significação na mediação das relações entre governo e sociedade civil - a AMO - ocorre com regularidade, a partir de regras claras e legítimas que possibilitam a tomada de decisões de forma partilhada entre sociedade organizada e representantes do poder público, objetivadas nas comissões de critérios de rateio de recursos, de organização e de fiscalização e acompanhamento.

Ao contrário, em Vitória, onde o OP vem sendo realizado ao longo de quatro gestões (1989 a 2004), tem-se observado variações substantivas no seu desenho institucional que refletem, em maioria, retrocessos e perdas, ao invés de aprendizados e avanços. As mudanças se materializaram na construção de um formato procedimental que, pouco a pouco, foi gerando uma simplificação no processo e a não manutenção de elementos deliberativos do desenho (como as assembléias e fóruns populares), de efeitos significativamente negativos à potencial repercussão dos processos participativos sobre a democracia. ${ }^{4}$

4 Desde 2002, a prefeitura de Vitória deixou de realizar assembléias nos bairros e passou a trabalhar com a chamada repactuação de obras, em que são incorporadas ao orçamento anual obras do OP ainda não realizadas, não sendo eleitas novas demandas. Em 2003 e 2004, pode- 
Os estudos têm demonstrado que a construção do formato institucional dos arranjos participativos guarda estreita relação com um dos requisitos do processo de participação - o compromisso e a vontade governamental em partilhar a tomada de decisão. Segundo Dagnino (2002), os resultados teóricos e práticos dos mecanismos de participação na gestão pública e os princípios de participação e eficácia ganham contornos muito diferenciados dependendo, dentre outras variáveis, dos projetos políticos dos governos aos quais estão subordinadas as experiências participativas. Para a autora, é da interseção entre os projetos políticos do governo e da sociedade e do quanto que estes se correspondem mutuamente que se pode obter a explicação para os resultados encontrados.

As substantivas alterações institucionais realizadas no OP de Vitória podem ser compreendidas à luz de sua relação com os projetos políticos governamentais. Verifica-se que são diferentes as concepções de participação e, por extensão, de democracia, das diferentes gestões que experimentaram o OP: o pressuposto democrático da administração do PT (gestão 1989-92) era a democracia participativa, em conseqüência, defendia-se a participação direta da população na formulação das políticas; nas três gestões seguintes do Psdb (1993 a 2004), com poucas variações, ao assumir a democracia representativa como forma de governo possível, exige-se uma participação apenas complementar, de conteúdo mais consultivo e legitimador, ao invés de deliberativo (Carlos, 2003; PMV, 2002).

Deste modo, verificou-se diferentes cenários políticos e institucionais. $\mathrm{Na}$ gestão do PT, quando foi implantado o OP, as regras eram claras, conhecidas e, sobretudo, construídas em conjunto com a sociedade organizada, na busca de um modelo de co-gestão da coisa pública que redefinisse papéis e responsabilidades. Verificou-se, neste período, a construção de canais efetivos de participação e ações de cunho pedagógica do executivo local, com vistas a promover uma participação propositiva e autônoma, em espaços de interlocução que viabilizassem a objetividade e a transparência na definição de objetivos comuns. Com a assunção do PSDB, as redefinições no formato metodológico do OP passaram a ocorrer em função do projeto político do governo e do papel que este atribui à democracia e à participação, ao invés da

se dizer que o OP inexistiu, embora seu órgão formal (Coordenadoria de Governo) continuasse com assento na Prefeitura e o mesmo não fizesse verbalmente tal afirmação. 
busca do aperfeiçoamento e aprofundamento do processo. Desde 1993, o OP em Vitória torna-se cada vez mais informal e experimental e as decisões mais significativas sobre o processo passaram a ser tomadas pela equipe do governo local, tendo o executivo como ator protagonista e centralizador, ocorrendo a participação popular apenas em caráter consultivo, o que fragilizou a autonomia da sociedade civil e a credibilidade no processo como um todo.

Por outro lado, a construção de uma nova institucionalidade depende igualmente (ou talvez até com mais centralidade) da forma como a sociedade organizada responde ao processo participatório. Em outras palavras, a consistência da cultura participativa, os vínculos associativos, a existência de organizações sociais sólidas e sua capacidade de articulação com outras entidades e atores e de atuar em arenas discursivas plurais e conflitivas, podem determinar as possibilidades de uma participação autônoma e da ocupação qualitativa da complexidade dos espaços participativos.

Em Vitória, somado ao quadro histórico de desarticulação, desmobilização, dependência e fragilidade da sociedade civil frente ao poder público, os critérios quantitativos de representação popular no orçamento participativo não são adequados a uma representatividade que numericamente favoreça a legitimidade das decisões tomadas. Os critérios de representação utilizados não se prendem a quorum nas reuniões de bairro, nem à população total do bairro, por exemplo, mas segue a orientação de um delegado efetivo (no total de 86) e um suplente por bairro, gerando um quantitativo limitado de delegados que pode levar ao comprometimento das decisões tomadas. Na verdade, este fato revela uma simplificação dos critérios de representatividade ou, mais duramente, uma falta de critérios construídos.

No caso de Serra, verifica-se um processo mais denso de quantificar a representação popular, que considera o número de entidades de bairro e o total de participantes nas assembléias, relacionando-se, assim, a organização e capacidade de mobilização social. Em Serra, os delegados do orçamento perfazem um total de 360 efetivos e igual número de suplentes.

A questão da representatividade, por outro lado, centra-se na qualidade da representação, que diz respeito aqui à autonomia dos representantes populares frente ao governo, entendida como a capacidade de sustentar opiniões, estabelecer acordos e defender posições de forma independente. Em Vitória, entre sociedade organizada e governo nota-se um padrão de relação extre- 
mamente frágil, em que pese a inexistência da participação efetiva e da deliberação democrática, em virtude, dentre outros fatores, da ausência ou pouca presença de sujeitos sociais autônomos. Um processo marcado por uma desqualificação da negociação e, por conseguinte, da representação, em que delegados do orçamento não possuem qualquer forma de normatização ou coordenação própria de suas ações; em que muitos destes desconhecem seu próprio papel; e, ainda, em que sua convocação e pauta de discussões são direcionadas e controladas pelo poder público municipal, caracterizando o pretérito predomínio da "cultura da dependência".

Em Serra, encontra-se um tecido social já mais consistente, destacandose a experiência de negociação e de exercício da autonomia do movimento popular. Observa-se uma representatividade qualitativa mais expressiva, cujo processo de negociação é bastante tenso e prolongado, o que revela a seriedade que o reveste, tanto para os delegados populares e sua instância articuladora (AMO) como para o governo.

Para a prática de autonomia dos representantes populares é de suma importância a transparência, a prestação de contas e a difusão de informação. O repasse de informações sobre todo o processo é imprescindível, tanto à população através dos delegados do orçamento, como para estes últimos através do poder público. Ter acesso à informação relevante e dominá-la é chave para um controle efetivo do processo de orçamento participativo, o que remete à questão do necessário tensionamento da máquina burocrática, de modo a torná-la adequada à construção partilhada das políticas.

No caso de Vitória, é previsto em uma das etapas do OP o treinamento dos delegados na finalidade de tornar acessíveis informações técnicas e, com isto, possibilitar maior acompanhamento e fiscalização da execução das obras. Porém, os delegados avaliam o treinamento como insuficiente ao devido controle público, agravado pelo não acontecimento da qualificação desde 2001.

Já em Serra, nota-se um maior investimento e esforço no processo de formação dos delegados e conselheiros do orçamento, promovido pela FAMS através de parceria com o CDDH, IDEA, UFES e pela Prefeitura através do NAOP (Núcleo e Acompanhamento do OP). 
O esforço dos atores envolvidos nos processos participativos em Serra, como prefeitura e entidades organizadas, em promover a participação tanto quantitativa como qualitativa também se verifica na variação dos dados de mobilização popular deste município em relação à Vitória. Em Serra, em 2002, o total de participantes no OP chegou a 9.133, mais que o dobro do alcançado em Vitória em 2001 (4.089 pessoas). Ainda em Serra, o percentual de população do município que participa das assembléias do OP representa em média $2,84 \%$ do total, ao passo que em Vitória a média municipal é de $1,39 \%$. Se considerarmos algumas regiões de Serra, como Praia II, Serra II e Praia I, este percentual salta para cerca de $4,63 \%$, enquanto em Vitória o maior percentual regional não passa de $2,95 \%$. A média de pessoas por assembléia também varia significativamente, já que em Serra o dado municipal é de 98 pessoas por reunião e em Vitória é de 52 participantes.

\section{O desafio do fortalecimento da sociedade civil e da participação autônoma}

Como foi dito, a definição de regras objetivas e públicas e sua apropriação pela população não dependem apenas do comprometimento político dos governos, mas também da "capacidade da população em ocupar os novos espaços institucionais de co-gestão, com independência e qualidade" (Carvalho e Felgueiras, 2000, p. 36).

A fragilidade da sociedade civil e principiante cultura de autonomia em relação ao poder público, conjugada à falta de maior tradição em práticas de negociação, de articulação do movimento e de elaboração de propostas concretas para as políticas de seu interesse, dá origem a um quadro histórico-cultural que necessariamente deve ser considerado no delineamento do modelo e das regras do OP, com vistas a proporcionar condições que visem auxiliar a população a compreender e assumir papéis nunca antes experimentados. Em outras palavras, nos casos de debilidade da sociedade civil é ainda mais importante a preocupação político-pedagógica, a formação de lideranças, a capacitação dos delegados, considerando que a autonomia e independência dos atores na sua relação com o governo são elementos fundantes na qualificação do processo de orçamento participativo. 
Abers (1997, p. 1749), no estudo de uma região de baixa densidade associativa no OP de Porto Alegre, demonstra o importante papel desempenhado pelo estado ao gerar um contexto favorável ao surgimento de novas associações, ao estimular os que participam com interesses imediatos a integrarem questões éticas de justiça distributiva na tomada de decisões, "transformando velhas formas 'contestatórias' de ativismo em ativismo positivo e propositivo; tornando abertas e participativas as associações antes fechadas e clientelistas". Seu estudo sugere que o sucesso da política de participação deriva de um profundo e persistente envolvimento de atores estatais que, direta e indiretamente, influenciam a organização da sociedade civil gerando impactos sobre a cultura política local.

Em Vitória, durante a gestão do PT (1989-1992), governo de Vitor Buaiz, verificou-se um esforço por parte do poder público, em manter uma relação democrática e transparente com a sociedade civil durante todo o processo de elaboração popular do orçamento, com o objetivo de reforçar a participação e a autonomia dos sujeitos políticos, colocando para si o papel da educação política.

$\mathrm{Na}$ experiência desta primeira gestão do OP na Capital, estudos realizados sobre este momento histórico permitem-nos registrar alguns avanços da política de participação para o movimento popular. ${ }^{5}$ As discussões do orçamento teriam proporcionado a abertura de processos democráticos no interior das entidades civis, principalmente das associações de moradores, como: a eleição de novas lideranças que expressassem os interesses da comunidade; o encontro e articulação de representantes populares em nível municipal em torno de objetivos comuns; a unificação de entidades que existiam no interior de um mesmo bairro como fruto do paralelismo; o desaparecimento de entidades fantasmas; o fortalecimento da instância federativa, o Conselho Popular de Vitória (CPV); as reivindicações passaram a ser colocadas em assembléias e sujeitas a votação, ao invés de submetidas a secretários municipais, prefeito e vereadores (Trindade e Moraes, 1992; Carvalhinho, 1992).

5 Muito embora o processo de implementação do OP nessa época incluísse apenas a participação das associações de moradores, estando ausentes do debate os setores não organizados da sociedade civil. 
Neste sentido, expõem a possibilidade da interação da sociedade civil com mecanismos efetivos de controle social na gestão pública poder representar avanços para os movimentos populares, quando postos a pensar políticas públicas, a colocar suas demandas de modo propositivo, a encaminhar suas necessidades e aspirações de forma realista e viável, enfim, em poder consubstanciar-se em uma contribuição para a construção identitária desses movimentos.

No entanto, de modo geral, estas transformações observadas nos padrões de organização popular não tiveram seu efeito generalizado, ou seja, não atingiram todas as entidades civis e nem na mesma medida, caracterizando um quadro de heterogeneidade político-cultural que ressalta cada entidade civil e, mais, cada ator social, como um elemento peculiar. Além disso, verificou-se que a população e suas entidades representativas não conseguiram ocupar todo o espaço aberto pelo poder público local, nem se posicionar em muitas das discussões propostas. No geral, a população não alcançou uma ampliação do nível de suas proposições e demandas, limitando-se, muitas vezes, a visões reivindicatórias e imediatistas, impossibilitando o controle efetivo da direção do processo de participação pela sociedade civil (Trindade e Moraes, 1992). Segundo Afonso e Ferraz (1994), na análise do conjunto de dificuldades e limites do processo participatório há que se considerar a própria fragilidade dos movimentos que "contam com poucos quadros, de modo geral sem formação política e com pouca experiência de relação com o poder público, o que os tornam presas fáceis de esquemas clientelistas e cooptativos".

A experiência de participação em Vitória tem demonstrado o peso exercido pela longa tradição de cultura política frágil e dependente sobre a tentativa de mudanças nos hábitos associativos do movimento popular, assim como, por outro lado, tem evidenciado a relevância do papel pedagógico do estado na realização prática da democracia participativa.

Assim, a concretização da possibilidade de fortalecimento da sociedade civil em seu escopo mais amplo, além do concreto investimento dos movimentos populares na sua qualificação técnica e política requer ainda um efetivo envolvimento das forças políticas governamentais, através do exercício de papéis e condutas político-pedagógicas que visem substanciar a organização de grupos e atores sociais. 
O orçamento participativo em Vitória obteve continuidade por três gestões do PSDB, muito embora o processo político pedagógico iniciado pela administração anterior do PT, de privilegiar e valorizar a participação da sociedade de forma propositiva, investindo na qualificação da participação e no fortalecimento do tecido social, ter sofrido grande desvalorização, de repercussões danosas para o movimento popular.

Deste modo, tem-se que na primeira gestão do PSDB, governo de Paulo Hartung (1993-1996), o OP sofreu significativas transformações em seu formato institucional que visavam à centralização do controle do processo participatório e à elaboração de propostas na equipe técnica de governo, através, sobretudo, do que ficou conhecido como "indicativo de obras da prefeitura". Da população era esperada uma participação consultiva, restrita ao referendamento e legitimação das propostas de intervenção do poder público local. Em virtude das críticas por parte do movimento popular, quanto à retirada de elementos do modelo procedimental do OP que favoreciam a realização prática dos princípios da democracia participativa, a segunda gestão do PSDB, governo de Luis Paulo Vellozo Lucas (1997-2000), investiu inicialmente na tentativa de recondução do processo participatório, no sentido, sobretudo, da reedição de algumas regras e procedimentos criadas durante a gestão do PT, que visassem resgatar a valorização da autonomia da sociedade civil na tomada de decisão. No entanto, como as mudanças empreendidas ainda estavam embebidas em um discurso de participação e de gestão democrática voltado meramente à legitimação e busca de respaldo político, o governo

6 A prefeitura municipal, através da construção de indicadores sócio-econômicos das regiões administrativas da cidade, passou a definir indicativos de obras e serviços para os bairros da cidade, ou seja, definir prioridades segundo as condições sociais e econômicas diagnosticadas. Os indicativos de obras deveriam obedecer ainda o realismo orçamentário, o critério de continuidade de obras iniciadas e a sintonia entre as necessidades do bairro com os da região e cidade. É nas assembléias de bairros do OP, que ocorre com a presença da equipe técnica da Prefeitura, que são apresentados aos moradores a situação financeira do município, a previsão de receita para o próximo ano, a execução das obras do OP no bairro e, o indicativo de prioridades de obras da prefeitura proposto para o bairro. Segundo Nacif (1995, p. 7), a Prefeitura foi acusada por alguns setores populares de "retrocesso político, de que se saiu da democracia de base para a obra indicada pela Prefeitura". Nota-se que a introdução de indicativos de obras propostos pela Prefeitura retira a premissa da população envolvida no processo de discussão do orçamento em definir suas próprias prioridades, inibindo o exercício político pedagógico de pensar de forma propositiva, realista e viável os problemas do bairro e da região. 
(reeleito para o mandato 2001-2004) foi, pouco a pouco, gerando uma simplificação no processo participatório, ignorando os elementos deliberativos do desenho e se descompromissando com a política de OP.

Em Vitória, a democracia pretendida nos governos do PSDB demonstrou-se refratária a uma concepção de democracia direta, por entendê-la como "negação do sistema representativo" (Nacif, 1995), ao invés de uma noção que considerasse a complementaridade entre os mecanismos de democracia representativa e de democracia participativa como condição necessária à ampliação do cânone democrático (Santos e Avritzer, 2002). Em conseqüência, desdobrou-se um movimento de fortalecimento das instâncias representativas de governo, através de processos de participação popular basicamente consultivo, com forte teor de centralismo e dirigismo, em prol da construção da credibilidade e legitimação governamental. Uma não coincidência e similaridade entre as intencionalidades políticas que subjazem as relações entre estado e sociedade civil, de fortes conseqüências para a efetivação dos potenciais impactos democratizantes do OP e para o exercício autônomo da sociedade civil na esfera pública.

\section{Acompanhamento e fiscalização da execução orçamentária}

O monitoramento das obras do OP é um ponto de grande fragilidade do processo, e ainda bastante informal e precário, nas duas experiências. As prefeituras apresentam prestações de contas anuais aos delegados, com maior ou menor regularidade e detalhamento, mas sempre restritas às obras do OP que constam do Plano de Investimentos, estando ausente do debate o controle público e acompanhamento da execução orçamentária como um todo.

A relação dos delegados com a população nos bairros e regiões e o repasse de informações sobre a execução orçamentária tem sido espontânea, de modo que só ocorre nos casos em que o delegado tem iniciativa, vínculos e experiência de trabalhar com grupos organizados. Deste modo, ainda que a metodologia adotada preveja entre as etapas do processo a fase de acompanhamento e fiscalização da execução orçamentária, a concentração do processo de participação popular em alguns meses do ano para elaboração do orçamento, a ausência de uma política mais ampla de participação voltada para continuidade do processo no cotidiano e os limites do movimento popu- 
lar, fazem com que toda a articulação social alcançada seja desfeita. O movimento, principalmente em Vitória, não consegue manter sua mobilização, fiscalizando e garantindo suas propostas. Além disso, na definição do plano de investimentos não se pode dizer que haja realmente um processo de negociação, pois os delegados não têm meios de avaliar mais profundamente as propostas do governo e de articular propostas alternativas, em virtude de suas limitações técnica e política para atuar em espaços discursivos e conflituosos.

Os governos, por sua vez, têm muita dificuldade em fazer previsões adequadas dos custos e do cronograma das obras, havendo uma grande inadequação da administração para produzir as informações necessárias ao monitoramento do plano de investimentos. O controle público sobre as decisões de governo parece ser, ao mesmo tempo, o maior "ganho" dos processos de OP e o maior desafio, ao tencionar a máquina pública e a lógica de governo provocando uma modernização que os tornaria mais adequados à transparência $\mathrm{e}$ democracia.

\section{Para além de prioridades concretas e materiais}

Nota-se nas experiências de Vitória e Serra uma grande limitação quanto à adoção de um processo de seleção de demandas concretas e materiais, como obras e serviços, ao invés de um processo articulado a hierarquização de prioridades temáticas e de políticas municipais, como se faz em outras experiências, por exemplo, através de plenárias e fóruns temáticos ou fóruns da cidade.

$\mathrm{Na}$ experiência de Serra, as discussões e eleição de demandas do OP ocorrem regionalmente, viabilizando a construção de Planos de Investimentos Regionais, onde os representantes dos bairros têm que priorizar os investimentos de acordo com o recurso previsto para cada região da cidade. Trata-se de um exercício pedagógico em que a população busca por uma visão que ultrapasse os limites do bairro, tendo que considerar as obras ou serviços de maior impacto social. Embora se observe entre os delegados do orçamento uma percepção que considera o processo participativo como um todo e, assim, menos voltado para a escala do bairro, as reivindicações e propostas ainda se limitam a prioridades concretas e materiais, ou seja, obras pontuais que, muitas vezes, fragmentam os recursos e podem distorcer um desenho mais integrado das políticas setoriais. 
No caso de Vitória a situação é ainda mais desalentadora. Ainda persiste uma grande dificuldade em se regionalizar as discussões e demandas do OP e constituir Planos de Investimentos Regionais. As transformações sofridas pela própria metodologia do OP, ao longo dos anos, demonstram a instabilidade no uso deste procedimento: a definição de demandas regionalmente ocorreu primeiramente no governo do PT; na primeira gestão do PSDB a escolha passou a ser por bairros; passando na sua segunda gestão a reiniciar a priorização de demandas por região, retornando, na sua terceira administração a ser por bairros.

A regionalização do OP em Vitória, em todo o seu processo, constitui-se um desafio tanto para o poder público como para o movimento popular. Embora o OP em Vitória esteja sendo realizado há mais de uma década, nota-se grande inexperiência da equipe de governo que o coordena quanto à condução do processo. Isto porque há uma descontinuidade na condução dos trabalhos e uma desconsideração quase que total da evolução da experiência como um todo - seus avanços e recuos. Desde 1989 a coordenação do OP passou pela Secretaria de Planejamento, pela Secretaria de Ação Social e desta para a Coordenadoria de Governo, não percebendo-se na estrutura organizacional da Prefeitura claramente qual é o lugar ocupado pelo OP. Além disso, salvo em seus primeiros anos de implantação, não percebe-se a existência de uma equipe técnica verdadeiramente comprometida com procedimentos político-pedagógicos que contribuam para a capacitação do movimento popular.

Como dito, o desafio também coloca-se ao movimento popular que, em Vitória, ainda é marcado por um perfil reivindicatório, imediatista e centrado em interesses em obter bens e melhorias na escala do bairro, mais sensível ao tecido social existente. Quando perguntado aos delegados do orçamento sobre sua principal motivação para participar das discussões do OP percebe-se respostas do tipo: "Lutar para que o que foi decidido como prioridade no bairro seja realizado." "Lutar por uma qualidade de vida melhor no bairro" (Questionário, 2000 apud Carlos, 2003).

Ainda há muito a construir, nos dois casos, quanto à discussão de prioridades temáticas articuladas a políticas públicas. Outras experiências, especialmente Porto Alegre e Belo Horizonte, demonstram a importância de se construir, fortalecer e articular o OP em outros espaços participativos, como entidades de defesa de direitos e de elaboração de políticas. Assim, a criação de esferas públicas plurais e a articulação entre sujeitos políticos podem abrir espaço a um controle mais aprofundado das finanças e das políticas públicas. 


\section{Considerações finais}

A análise dos resultados do orçamento participativo em Vitória e Serra, conduzido a partir de sua relação com um dos elementos condicionantes das práticas sociais - a cultura política local -, considerando a complexidade dos processos, não recorre a essa variável de modo absoluto ou determinante, mas antes como recurso que constrange ou potencializa a participação, podendo mover-se para diferentes direções em virtude de sua interlocução com outras variáveis presentes no processo democrático.

A participação em Vitória, marcada por um padrão de relações clientelísticas e paternalistas, com um movimento popular debilmente articulado e desqualificado técnica e politicamente para protagonizar processos e disputar hegemonias, não alcançou modificações significativas na forma de mediação de interesses entre a esfera do estado e a esfera da sociedade, registrando-se muito mais como um ato ritualizado e destituído de sentido crítico e emancipador. Mesmo sendo a representação popular no OP composta por sujeitos políticos de perfil associativista, apresentando vínculos com entidades comunitárias, filiação sindical e partidária e, por outro lado, de consideráveis percepções sobre sua competência política e sobre a importância dos processos de participação, estes atores não conseguiram desenvolver papéis protagonizadores na interação comunicativa. Antes disso, mediam interações a partir de uma participação de caráter passivo, de conteúdo até paternalista, de quem deseja ser ouvido, atendido, mas não enfrenta o desafio do diálogo público com vistas à construção de decisões compartilhadas. Não há uma prática participatória enquanto uma interferência efetiva no poder público, que implique conhecimento, decisão e responsabilidade, enfim, que implique em capacidades comunicativas e dialogais (Habermas), capazes de tencionar os padrões de relação estado e sociedade, ao revés da simples adequação das novas instâncias institucionais às antigas práticas.

Em Serra, por sua vez, a trajetória de busca de conquistas, de disputas na arena decisória e de articulação entre as entidades, contribuiu significativamente para o fortalecimento da sociedade civil e, por conseguinte, para as expressões da participação no orçamento municipal. Na percepção dos sujeitos políticos locais, que reclamam o constante aperfeiçoamento da experiência de participação, o orçamento participativo gerou melhorias no funcionamento da máquina administrativa, no sentido do aumento da transparência e 
controle sobre o dinheiro público, no aumento da qualidade das obras controladas e, principalmente, na efetivação da participação popular na gestão pública, contribuindo para a ampliação da democracia. Avaliam ainda o OP como sendo um instrumento de organização e reivindicação popular de impactos relevantes para o movimento social, que mobiliza lideranças e fortalece as entidades de bairro e, por outro lado, compromete o poder público na execução das prioridades definidas. Nas palavras da presidente da Fams: "Nosso desafio é torná-lo [OP] um instrumento de qualificação da vida do povo serrano, aumentando seu valor global aplicado, extinguindo sua condição de barganha de algumas lideranças de bairro, quantificando e qualificando as lideranças para a participação nesse espaço democrático." (Entrevista em 03/02/2002 apud Carlos, 2003).

A literatura tem asseverado o papel da cultura política local, da tradição de participação em arenas discursivas, para a realização dos potenciais impactos democratizantes da participação. Entende-se que a amplitude e complexidade desta questão, aqui apenas ensaiada, exige maior esforço de compreensão acerca dos diálogos, confluências e influências recíprocas presentes nas relações que envolvem sociedade, instituição e estado. Nestes termos, frente a determinados quadros políticos e institucionais, o quadro societário movimenta-se, gerando adesões, resistências, novas conformações, e viceversa: uma dinâmica que denuncia a relação de reciprocidade e de interferência mútua entre os elementos que alimentam interações políticas e práticas cotidianas.

\section{Referências}

ABERS, Rebecca. Do clientelismo à cooperação: governos locais, políticas participativas e organização da sociedade civil em Porto Alegre. Cadernos Ippur/Ufrj. Rio de Janeiro: Ufrj/Ippur, ano 12, n. 1, p. 47-78, jan.-jul. 1998.

AFONSO, M.; FERRAZ, A. T. Poder local , democratização e participação popular: a experiência de Vitória. Anpocs, 18, Caxambu, 1994.

ALVAREZ, S.; DAGNINO, E.; ESCOBAR, A. (orgs.). Cultura política nos movimento sociais latino-americanos. Minas Gerais: Ed. Ufmg, 2000.

AVRITZER, Leonardo. A moralidade da democracia: ensaios em teoria habermasiana e teoria democrática. São Paulo: Perspectiva; Belo Horizonte: Ed. Ufmg, 1996. 
. Cultura política, atores sociais e democratização: uma crítica as teorias da transição para a democracia. Revista de Ciências Sociais, n. 28, p. 101-122, 1995.

— Modelos de deliberação democrática: uma análise do orçamento participativo no Brasil. In: SANTOS, B. S. (org.). Democratizar a democracia participativa: os caminhos da democracia participativa. Rio de Janeiro: Civilização Brasileira, p. 561597, 2002.

; NAVARRO, Z. (orgs.). A inovação democrática no Brasil: o orçamento participativo. São Paulo: Cortez, 2003

CARLOS, Euzineia. Controle social e política redistributiva: as experiências de orçamento participativo em Vitória e Serra, ES. Rio de Janeiro, 207 p. Dissertação (Mestrado). Instituto de Pesquisa e Planejamento Urbano e Regional/Ippur da Universidade Federal do Rio de Janeiro, 2003.

CARVALHINHO, A. P. G. (1992). Participação social: análise crítica da experiência em Vitória, ES. Vitória, Monografia (graduação). Departamento de Administração da Universidade Federal do Espírito Santo.

CARVALHO, M. C. A. A.; FELGUEIRAS D. Orçamento participativo no ABC: Mauá, Ribeirão Pires e Santo André. Polis. São Paulo: Pólis, n. 34, 2000.

DAGNINO, Evelina. Os movimentos sociais e a emergência de uma nova noção de cidadania. In: —_. (org.). Anos 90: política e sociedade no Brasil. São Paulo: Brasiliense, 1994.

. Cultura, cidadania e democracia: a transformação dos discursos e práticas na esquerda latino-americana. In: ALVAREZ, S.; DAGNINO, E.; ESCOBAR, A. (orgs.). Cultura política nos movimento sociais latino-americanos. Minas Gerais: Ed. Ufmg, 2000, p. 61-101.

. Sociedade civil, espaços públicos e a construção democrática no Brasil. In: - . (org.) Sociedade civil e espaços públicos no Brasil. São Paulo: Paz e Terra, 2002.

HABERMAS, J. Mudança estrutural da esfera pública: investigações quanto a uma categoria da sociedade burguesa. Rio de Janeiro: Tempo Brasileiro, 1984.

HERKENHOFF, Beatriz (1995). O papel do líder comunitário. Vitória: Ufes.

LÜCHMANN, Ligia. H. H. Possibilidades e limites da democracia deliberativa: a experiência do Orçamento Participativo de Porto Alegre. Campinas, Tese (Doutorado), Instituto de Filosofia e Ciências Humanas da Universidade Estadual de Campinas, 2002.

MACHADO, M. B. S. O movimento de bairro na discussão do orçamento municipal. Vitória, Monografia (graduação). Departamento de Serviço Social da Universidade Federal do Espírito Santo, 1990.

NACIF, Vera. A experiência da Prefeitura de Vitória. In: Seminário democracia e poder local. Rio de Janeiro, 1995. 
PATEMAN, Carole]. Participação e teoria democrática. Rio de Janeiro: Paz e Terra, 1992.

PREFEITURA MUNICIPAL DE VITÓRIA. Estudo movimento reivindicatório de bairros do município de Vitória. Vitória, mimeo, 1990.

Agenda 21 - administração municipal: relações de intermediação entre sociedade civil e municipalidade no governo da cidade de Vitória (versão preliminar). Vitória, mimeo, 2002.

SANTOS, Boaventura Souza; AVRITZER, Leonardo. Para Ampliar o cânone democrático. In: SANTOS, B. S. (org.). Democratizar a democracia: os caminhos da democracia participativa. Rio de Janeiro: Civilização Brasileira, 2002.

SANTOS, Boaventura Souza. Introdução geral à coleção. In: —_ . (org.). Democratizar a democracia. Os caminhos da democracia participativa. Rio de Janeiro: Civilização Brasileira, 2002a.

- Orçamento Participativo em Porto Alegre: para uma democracia redistributiva. In:- . (org.). Democratizar a democracia participativa: os caminhos da democracia participativa. Rio de Janeiro: Civilização Brasileira, 2002b, p. 455-559.

TEIXEIRA, Ana Saleti M. Orçamento Participativo em Serra, ES: um relato da discussão nos anos de 1995, 1996, 1997, 1998, 1999 e 2000. Serra: PMS, 2000.

TEIXEIRA, Elenaldo. O local e o global: limites e desafios da participação cidadã. $3^{\text {a }}$ ed. São Paulo: Cortez, 2002.

TRINDADE, Auta F.; MORAES, Jorge S. G. de. Participação popular no orçamento da Prefeitura de Vitória. Revista Proposta, n. 54, 1992.

Recebido em 18 de dezembro de 2005 e aprovado em 4 de fevereiro de 2006 